\title{
Chapter 7 \\ Enhancing Functionalities of Metallic Materials by Controlling Phase Stability for Use in Orthopedic Implants
}

\author{
Masaaki Nakai, Mitsuo Niinomi, Ken Cho, and Kengo Narita
}

\begin{abstract}
This chapter aims to review the recent trends pertaining to the enhanced functionalities, including low Young's modulus, self-tunable Young's modulus, and low magnetic susceptibility, of titanium and zirconium alloys for use in orthopedic implants. These value-added functionalities can be realized by controlling the type of crystal structure and their lattice structure stabilities, which are related to the phase stability of titanium and zirconium alloys.
\end{abstract}

Keywords Magnetic susceptibility - Metallic materials • Orthopedic implant

- Phase stability • Young's modulus

\subsection{Introduction}

One of the most important factors concerning the use of orthopedic implants is to ensure safety in usage, which is often associated with their mechanical reliability to endure physiologically cyclic loading and unexpected large loads during treatment. Given these considerations, metallic materials are advantageous over ceramic and polymeric materials for use as implantable materials. Therefore, more than $80 \%$ of the implant devices used till date are made of metallic materials [1]. Another important factor concerning the use of orthopedic implants is their toxicity toward living tissues. In general, the human body inherently resists any incoming toxic element. In other words, human body exhibits low permittivity to highly toxic elements eluted from orthopedic implants [2]. That is, the toxicity of orthopedic implants depends not only on the nature of the metallic elements but also on the amount of them, which, in turn, strongly depends on the corrosion resistance of each metallic material. Therefore, in the human body, a metallic material with high corrosion resistance is highly imperative to ensure their safe usage as orthopedic implants.

M. Nakai $(\varangle) \bullet$ M. Niinomi $\bullet$ K. Cho $\bullet$ K. Narita

Institute for Materials Research, Tohoku University, 2-1-1 Katahira,

Aoba-ku, Sendai 980-8577, Japan

e-mail: nakai@imr.tohoku.ac.jp 
Conventionally, industrial metallic materials with high corrosion resistance, such as stainless steels (SUS316L), titanium (Ti) alloys (CP Ti and Ti-6Al-4V ELI alloys), and cobalt (Co) alloys (Co-Cr alloys), have been widely used in biomedical applications [3]. Among these materials, Ti alloys have recently attracted considerable attention because of the feasibility of imparting improved functionalities to orthopedic implants. For instance, Ti undergoes allotropic transformation at $1,155 \mathrm{~K}$, which is considered to be very important in terms of phase stability to obtain various functions. In simple terms, Ti alloys can be tuned to perform special functions by adept control of phase stability by varying the chemical composition. In addition, zirconium $(\mathrm{Zr})$, which is one of the congeners of $\mathrm{Ti}$, has also received considerable attention, and new $\mathrm{Zr}$ alloys for orthopedic implants have been developed on the basis of phase stability.

In this chapter, we have reviewed the latest trends in the development of $\mathrm{Ti}$ and $\mathrm{Zr}$ alloys for orthopedic implants with special functionalities, especially those obtained by controlling phase stability.

\subsection{Low Young's Modulus}

During orthopedic surgery, the use of metallic material with Young's modulus higher than that of the bone can lead to excess bone resorption due to the inhibition of load transfer to the bone (stress shielding effect) [4, 5]. Among the different metallic materials, Ti alloys exhibit high strength and relatively low Young's modulus. Furthermore, among the different Ti alloys, $\beta$-type Ti alloys consisting of bcc- $\beta$ phase generally exhibit Young's modulus lower than those of $\alpha$-type and $(\alpha+\beta)$-type Ti alloys consisting of hcp- $\alpha$ and $($ hcp- $\alpha+$ bcc- $\beta$ ) phases, respectively. This can be attributed specifically to their crystal structures, as shown in Fig. 7.1 [6]. Given this consideration, several studies have focused on the reduction of the Young's modulus of $\beta$-type Ti alloys closer to that of the bone [7-13].

The Young's modulus of $\beta$-type Ti alloys is considered to be closely related to the stability of the $\beta$-phase. For example, the Young's modulus of Ti-Nb alloys, which is quenched above the $\beta$ transus temperature, depends on the niobium (Nb) content $[14,15]$. Depending on the chemical composition, Ti alloys exhibit some intermediate phases, such as non-equilibrium hcp- $\alpha^{\prime}$, orthorhombic- $\alpha^{\prime \prime}$, and hexagonal- or trigonal- $\omega$ phases between the equilibrium $\alpha$ and $\beta$ phases [17]. As a function of the chemical composition, the Young's modulus of Ti-Nb alloys shows local maximum at the chemical composition in which the $\omega$ phase is formed by quenching ( $\mathrm{Ti}-30 \mathrm{Nb})$. Conversely, the Young's modulus of $\mathrm{Ti}-\mathrm{Nb}$ alloys shows local minimum at the chemical composition in which the lowest $\mathrm{Nb}$ content in the range of the non- $\omega$ phase is formed by quenching $(\mathrm{Ti}-40 \mathrm{Nb})[14,15]$. This implies that the formation of the $\omega$ phase has to be suppressed in order to obtain low Young's modulus in $\beta$-type Ti alloys [16]. Furthermore, studies on the temperature dependence of the Young's moduli of $\mathrm{Ti}-\mathrm{Nb}-\mathrm{Al}[11]$ and $\mathrm{Ti}-\mathrm{Nb}-\mathrm{Sn}[9,16]$ alloys show that their Young's moduli reduce close to their $\alpha^{\prime \prime}$ martensitic transformation temperature. Figure 7.2 [11] shows a typical example of this case in $\mathrm{Ti}-24 \mathrm{Nb}-3 \mathrm{Al}$ 


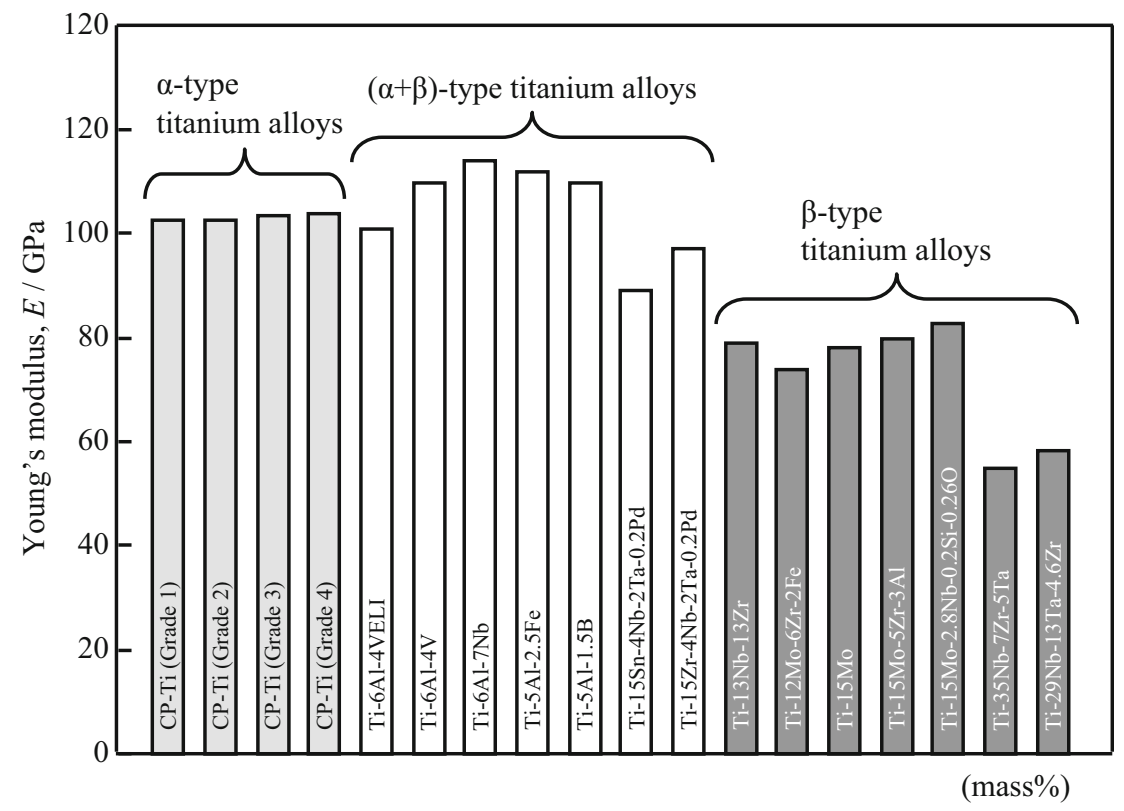

Fig. 7.1 Young's moduli of $\alpha-,(\alpha+\beta)-$, and $\beta$-type titanium alloys [6]

Fig. 7.2 Dependence of Young's modulus of a $\beta$-type titanium alloy with low Young's modulus (Ti-24Nb-3Al alloy (mol $\%)$ ) on temperature. $\phi$ is angles between longitudinal and rolling directions in specimen, and $\mathrm{M}_{\mathrm{s}}$ is $\alpha^{\prime \prime}$ martensitic transformation temperature [11]

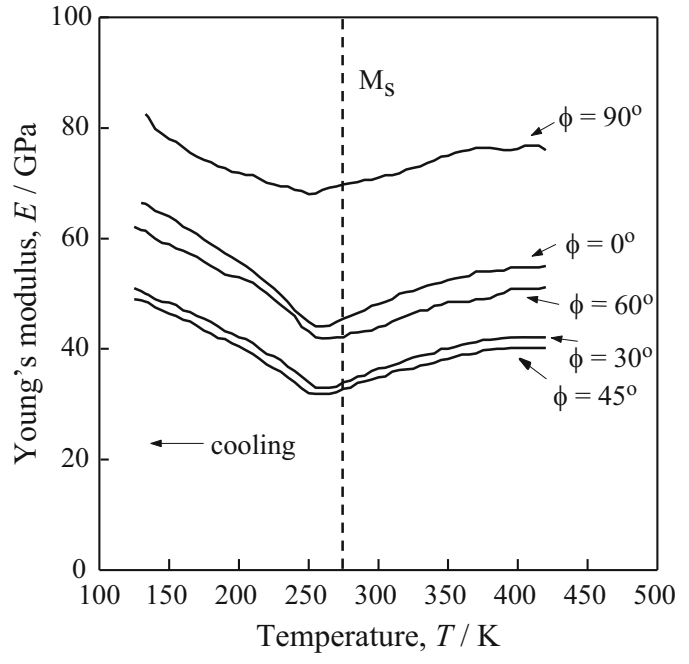

alloys (only the chemical composition of this alloy is expressed using mol\% in this chapter). Therefore, in order to obtain the lower Young's modulus of $\beta$-type Ti alloys closer to room temperature or body temperature, the chemical composition of the alloys should be determined to be their $\alpha^{\prime \prime}$ martensitic transformation 
temperatures just below these temperatures [16]. Newly developed $\beta$-type Ti alloys such as Ti-Nb-Ta-Zr [7, 8], Ti-Nb-Sn [16, 9, 15], Ti-Nb-Al [11, 17], Ti-Nb-Ta [18], and $\mathrm{Ti}-\mathrm{Nb}-\mathrm{Zr}-\mathrm{Sn}$ [10] alloys are considered to satisfy the abovementioned requirements for obtaining low Young's modulus of the order of 40-60 GPa, which is close to that of the bone (10-30 GPa) [19].

However, the mechanical reliability of these $\beta$-type Ti alloys with low Young's modulus is typically lesser than that of a common $(\alpha+\beta)$-type Ti-6Al-4V ELI alloy. Therefore, improvement in the mechanical reliability of $\beta$-type Ti alloys with low Young's modulus is currently under study [20,21]. The static strength, namely, the tensile strength and $0.2 \%$ proof strength of $\beta$-type Ti alloys with maintaining low Young's modulus can be achieved to the level of those of Ti-6Al-4V ELI alloy by severe cold working such as severe cold rolling, swaging and forging, and severe plastic deformation such as high pressure torsion (HPT) $[5,22,23]$. However, the dynamic strength, namely, the fatigue strength with maintaining low Young's modulus cannot be improved by severe cold working or severe plastic deformation [24]. Therefore, to improve fatigue strength of $\beta$-type $\mathrm{Ti}$ alloys, introducing the secondary phases such as $\alpha$ and $\omega$ phases, which are formed by aging, in the $\beta$-phase matrix is effective, but increases the Young's modulus. Therefore, controlling the amount of the secondary phase should be considered to maintain the Young's modulus as low as possible. One of the way to introduce a small amount of the secondary phase is short-time aging at a relatively low temperature. In this case, the $\omega$ phase is attractive because it increases remarkably the strength of $\beta$-type Ti alloys although increasing the Young's modulus. For example, as a result of introducing a small amount of the $\omega$ phase by the sort-time aging, the fatigue strength of Ti-29Nb-13Ta-4.6Zr alloy, which is one of the $\beta$-type Ti alloys with low Young's modulus for biomedical applications, increases to a level of that of Ti-6Al-4V ELI alloy while maintaining its Young's modulus around $75 \mathrm{GPa}$ [20]. Furthermore, introducing a small amount of ceramics such as $\mathrm{TiB}$ and $\mathrm{Y}_{2} \mathrm{O}_{3}$ to the $\beta$-phase matrix is also effective to improve the fatigue strength of $\beta$-type Ti alloys [21, 25]. Figure 7.3 [21] shows maximum cyclic stress-fatigue life (the number of cycles to failure) curves, namely, S-N curves of Ti-29Nb-13Ta-4.6Zr alloys with different $\mathrm{Y}_{2} \mathrm{O}_{3}$ additions obtained from fatigue tests where the amounts of $\mathrm{Y}_{2} \mathrm{O}_{3}$ are expresses as $\mathrm{Y}$ concentrations. The fatigue strength is highly improved by $\mathrm{Y}_{2} \mathrm{O}_{3}$ additions both in low- and high-cycle-fatigue life regions, where the number of cycles to failure is less than $10^{5}$ cycles and exceeds $10^{5}$ cycles, respectively. The fatigue limit of the alloy with 0.1 mass $\% \mathrm{Y}$ is the greatest among the alloys with different $\mathrm{Y}$ concentrations. Young's moduli of Ti-29Nb-13Ta-4.6Zr alloys with different $\mathrm{Y}_{2} \mathrm{O}_{3}$ additions are shown in Fig. 7.4 [21]. It indicates that Young's moduli of Ti-29Nb-13Ta-4.6Zr alloys with different $\mathrm{Y}_{2} \mathrm{O}_{3}$ additions are almost similar to that of $\mathrm{Ti}-29 \mathrm{Nb}-13 \mathrm{Ta}-4.6 \mathrm{Zr}$ alloy without $\mathrm{Y}_{2} \mathrm{O}_{3}$ addition, which is around $60 \mathrm{GPa}$. 
7 Enhancing Functionalities of Metallic Materials by Controlling Phase...

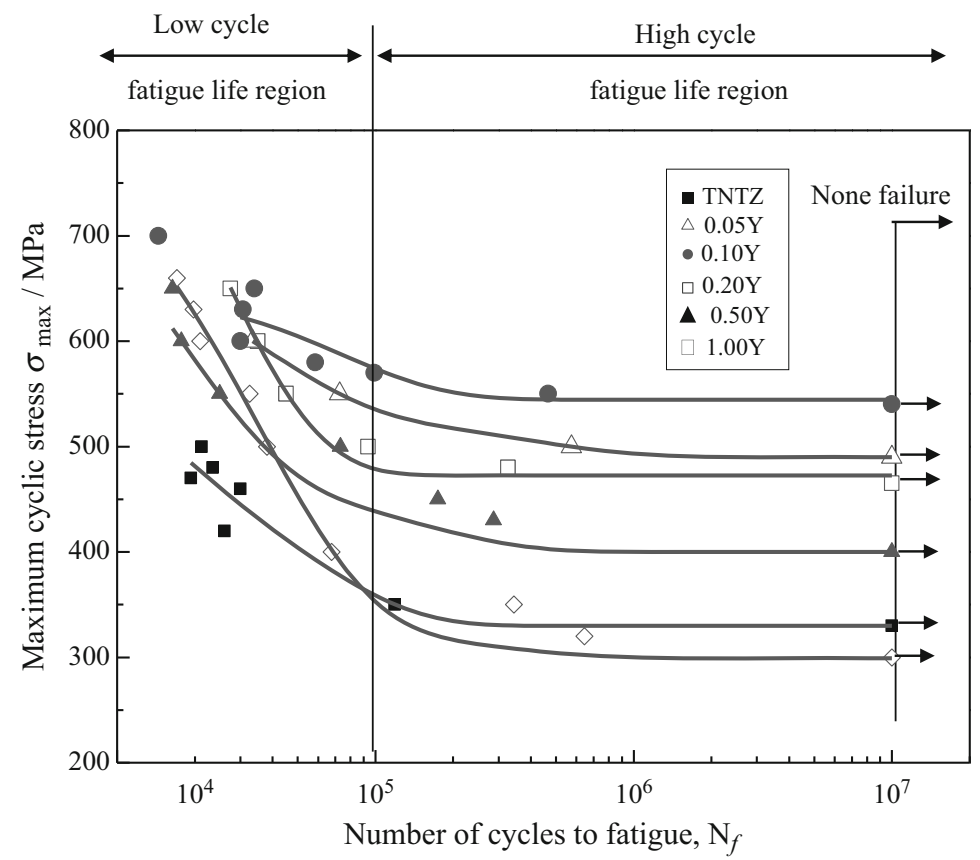

Fig. 7.3 S-N curves of cold-rolled Ti-29Nb-13Ta-4.6Zr alloys (mass\%) without and with different $\mathrm{Y}_{2} \mathrm{O}_{3}$ additions which are shown as contents [21]

Fig. 7.4 Young's moduli of cold-rolled Ti-29Nb13Ta-4.6Zr alloys (mass\%) without and with different $\mathrm{Y}_{2} \mathrm{O}_{3}$ additions as a function of content [21]

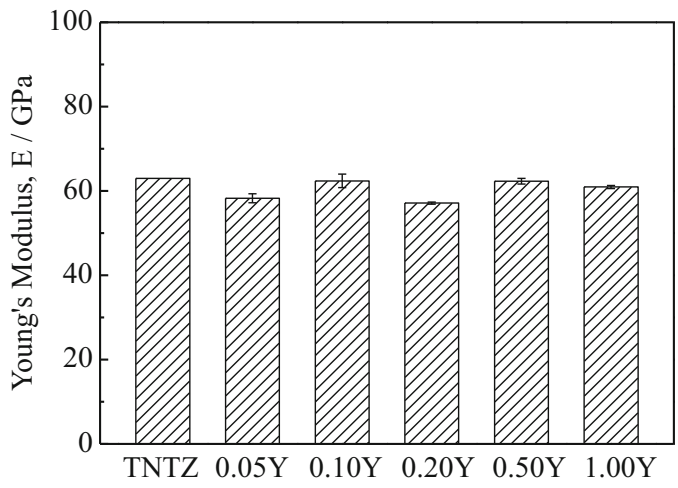

\subsection{Wear Properties of Low Young's Modulus Titanium Alloy}

Some orthopedic implants consist of more than one component with metal-to-metal contacts such as spinal fixation devices so that the wear properties of materials is important for use in such the applications. A difference of wear behavior between 


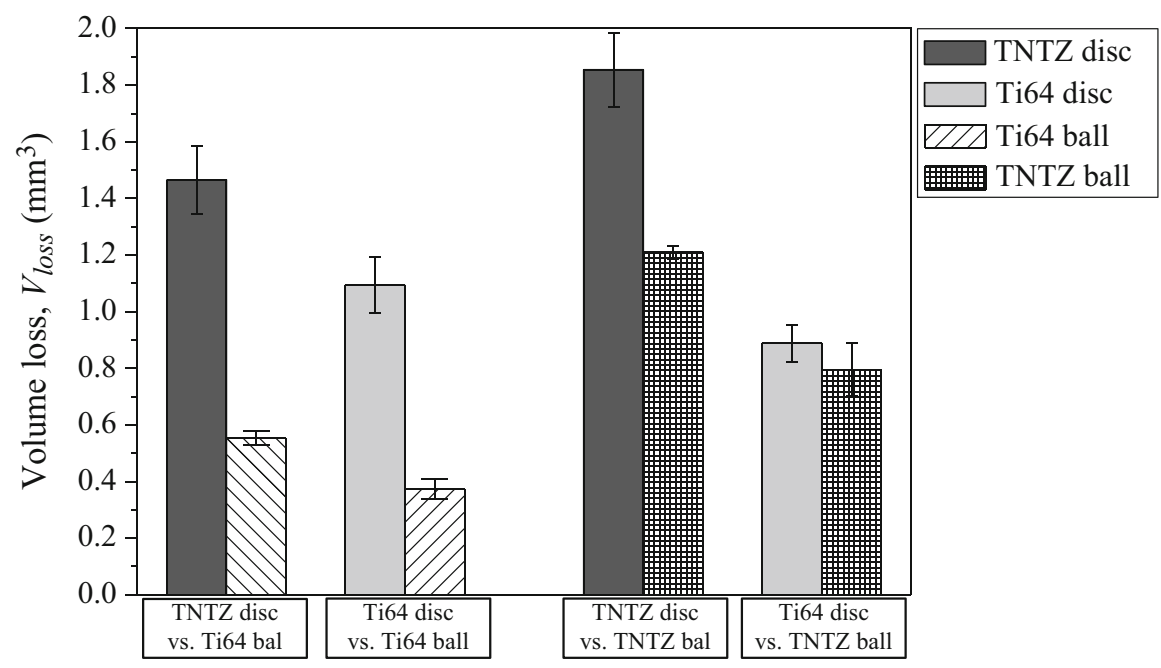

Fig. 7.5 Volume losses of discs and balls made of Ti-6Al-4V ELI alloy (mass\%) (Ti64) and Ti$29 \mathrm{Nb}-13 \mathrm{Ta}-4.6 \mathrm{Zr}$ alloy (mass\%) (TNTZ) obtained from the frictional wear tests [26]

Ti-6Al-4V ELI alloy and Ti-29Nb-13Ta-4.6Zr alloy was investigated [26, 27]. Volume loss of Ti-29Nb-13Ta-4.6Zr alloy was larger than that of Ti-6Al-4V ELI alloy for both discs and balls (mating materials) in the ball-on-disc type wear testing as shown in Fig. 7.5 [26]. According to wear track observations shown in Fig. 7.6 [27], continuous uniform groove and micro cutting, indicative of abrasion, and oxide debris are observed on the worn surface of Ti-6Al-4V ELI alloy. On the other hand, severe plowing, massive surface deformation, many cracks, and some traces of spalling in the form of platelets, indicative of delamination, are observed on the worn surface of $\mathrm{Ti}-29 \mathrm{Nb}-13 \mathrm{Ta}-4.6 \mathrm{Zr}$ alloy. These observation results indicate that the resistance to plastic shearing of $\mathrm{Ti}-29 \mathrm{Nb}-13 \mathrm{Ta}-4.6 \mathrm{Zr}$ alloy is lower than that of Ti-6Al-4V ELI alloy, which is intrinsically related to low Young's modulus, resulting in different wear behaviors between these two alloys.

\subsection{Self-Tunable Young's Modulus}

In case of spinal fixation devices, high rigidity can increase the risks of stress shielding effect and adjacent segment degeneration. Therefore, materials with low Young's modulus are often preferred to realize healthy spine formation [28, 29]. However, these devices also require high Young's modulus as they are subjected to bending during surgery to obtain the physiological curvature of the spine [30]. In this case, the device must be bent within a limited space inside the patient's body. Therefore, it is often difficult for the surgeon to make an intended curvature if the spring-back of the spinal fixation devices is relatively large [31]. Furthermore, it has 

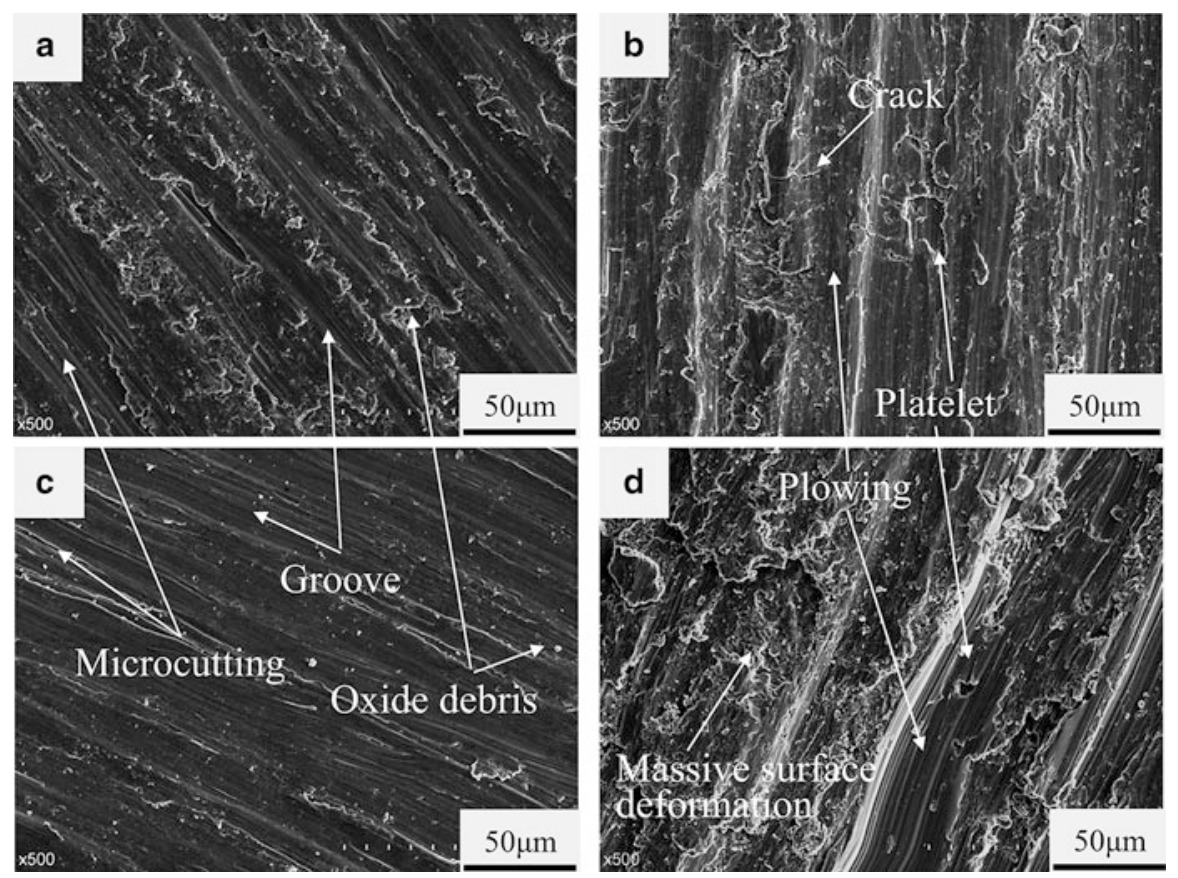

Fig. 7.6 Scanning electron micrographs of worn surfaces of a $\beta$-type titanium alloy with low Young's modulus (Ti-29Nb-13Ta-4.6Zr alloy (mass\%) (TNTZ)) and a conventional $(\alpha+\beta)$ type titanium alloy (Ti-6Al-4V ELI alloy (mass\%) (Ti64)) after ball-on-disc wear tests; (a) Ti64 disc against Ti64 ball, (b) TNTZ disc against Ti64 ball, (c) Ti64 disc against TNTZ ball, and (d) TNTZ disc against TNTZ ball [27]

been reported that the bending tool used by a surgeon to bend the device often leads to scratches on the device surface during the surgery. This, in turn, decreases the mechanical reliability of the spinal fixation devices [32]. Large spring-back leads to difficulty in bending, resulting in the repetition of contouring during operation. This increases the risk of failure of spinal fixation devices [33]. The degree of springback depends on both the strength and Young's modulus of spinal fixation devices. Given the same strength, it is the spinal fixation devices with higher Young's modulus that will exhibit a smaller spring-back. That is, these devices are often preferred to suppress the spring-back [34]. Therefore, there is a conflicting requirement in Young's modulus from the viewpoint of patients and surgeons, which cannot be completely satisfied by $\beta$-type Ti alloys with low Young's modulus [31]. In order to overcome this issue, recent studies have proposed a novel concept using a deformation-induced $\omega$-phase transformation in $\beta$-type Ti alloys [31], such as Ti-Cr [35], Ti-Mo [36], Ti-Zr-Mo [37], Ti-Zr-Mo-Cr [38], and Ti-Cr-O [39] alloys. These materials exhibit novel functionality, wherein the deformed material possesses high Young's modulus, while the non-deformed part has low Young's modulus. This is made possible by the phenomenon of deformation-induced 
Fig. 7.7 Young's moduli of $\beta$-type titanium alloys with self-tunable Young's modulus (Ti-12Cr alloy (mass\%)) and low Young's modulus (Ti-29Nb-13Ta4.6Zr alloy (mass\%)) [31]

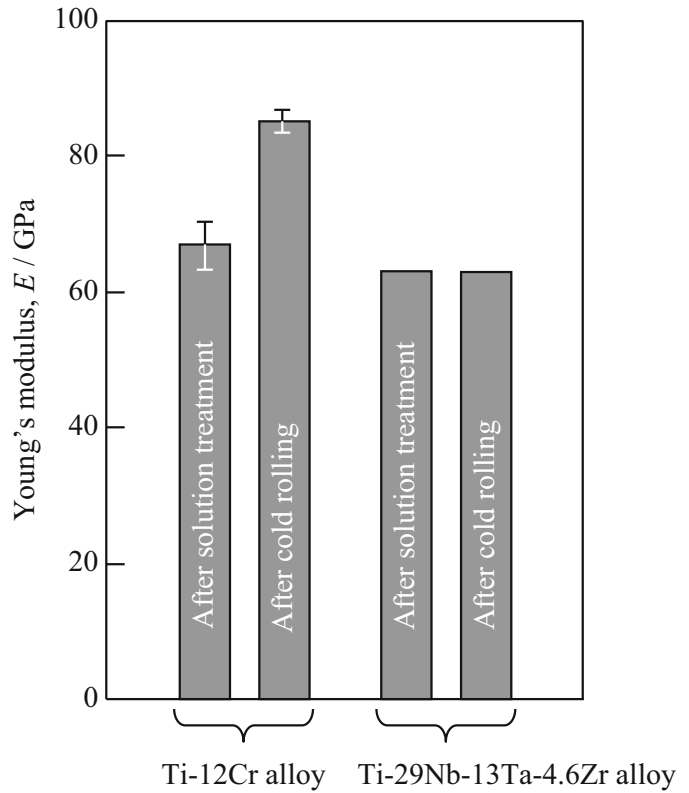

$\omega$-phase transformation localized within the deformed part of the material, which provides an opportunity to satisfy the conflicting requirement in terms of Young's modulus.

Figure 7.7 [31] shows the Young's moduli of $\beta$-type Ti alloys, Ti-12Cr alloy with self-tunable Young's modulus and $\mathrm{Ti}-29 \mathrm{Nb}-13 \mathrm{Ta}-4.6 \mathrm{Zr}$ alloy with low Young's modulus, after being subjected to solution treatment and cold rolling. The Young's moduli of both $\mathrm{Ti}-12 \mathrm{Cr}$ and $\mathrm{Ti}-29 \mathrm{Nb}-13 \mathrm{Ta}-4.6 \mathrm{Zr}$ alloys subjected to solution treatment are almost similar of the order of 60-70 GPa. After being subjected to cold rolling, $\mathrm{Ti}-29 \mathrm{Nb}-13 \mathrm{Ta}-4.6 \mathrm{Zr}$ alloy, in which no phase transformation occurs during cold rolling, reveals Young's modulus almost similar to that subjected to solution treatment. Conversely, the Young's modulus of $\mathrm{Ti}-12 \mathrm{Cr}$ alloy is found to increase with cold rolling. The microstructure of $\mathrm{Ti}-12 \mathrm{Cr}$ alloy after cold rolling, as observed using a transmission electron microscope, indicates the formation of the $\omega$ phase. In general, the formation of the $\omega$ phase significantly increases the Young's modulus of $\beta$-type Ti alloys [24]. Therefore, the observed increase in Young's modulus of Ti-12Cr alloy as a result of cold rolling could be attributed to the deformation-induced $\omega$ phase transformation $[31,35]$. The increase in Young's modulus due to the deformation-induced $\omega$ phase transformation was also confirmed experimentally, as shown in Fig. 7.8 [35], which indicates that the spring-back of $\mathrm{Ti}-12 \mathrm{Cr}$ alloy could be suppressed in comparison to that of $\mathrm{Ti}-29 \mathrm{Nb}-13 \mathrm{Ta}-4.6 \mathrm{Zr}$ alloy. 
Fig. 7.8 Springbaks of $\beta$-type titanium alloys with self-tunable Young's modulus (Ti-12Cr alloy (mass\%)) and low Young's modulus (Ti-29Nb-13Ta4.6Zr alloy (mass\%)) [35]

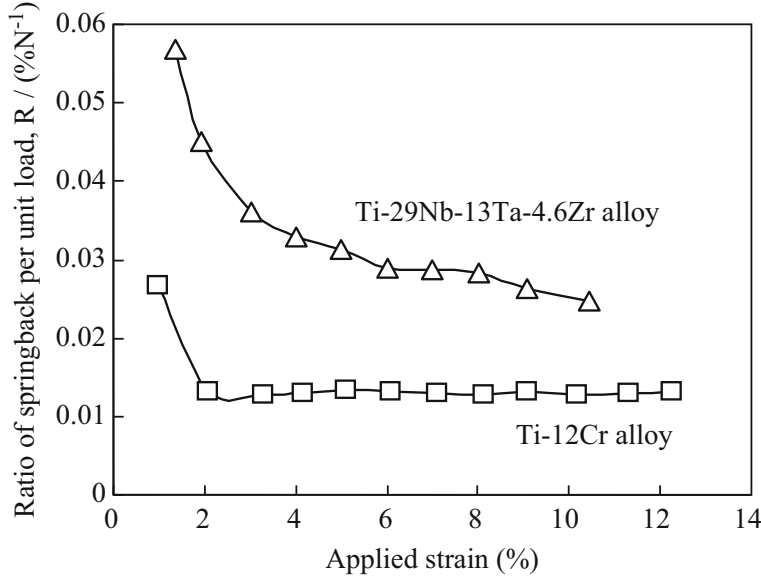

\subsection{Low Magnetic Susceptibility}

Conventionally, magnetic resonance imaging (MRI) is used for the diagnosis of various diseases. However, when metallic orthopedic devices are implanted in the human body, deficits and distortions are formed in the images of organs and tissues around the implant (artifact), hindering the exact diagnosis performed using a MRI. The artifacts formed by the metallic materials could be ascribed mainly to the difference in magnetic susceptibilities between living tissues and metallic materials [2]. The magnetic susceptibility of living tissues reveals diamagnetism, while that of water being $-9 \times 10^{-6} \mathrm{~cm}^{3} \mathrm{~g}^{-1}$ [40]. On the other hand, Ti, being paramagnetic, has the magnetic susceptibility of $3.2 \times 10^{-6} \mathrm{~cm}^{3} \mathrm{~g}^{-1}$ [41]. This magnetic susceptibility of $\mathrm{Ti}$ is much lower than that of ferromagnetic iron ( $\mathrm{Fe})$ and $\mathrm{Co}$, but still higher than that of water. Therefore, $\mathrm{Zr}$, which is a congener of $\mathrm{Ti}$, also exhibits a smaller magnetic susceptibility of $1.3 \times 10^{-6} \mathrm{~cm}^{3} \mathrm{~g}^{-1}$, [41]. This property has gained significant attention, and it forms the genesis for the recent developments of $\mathrm{Zr}$ alloys, such as $\mathrm{Zr}-\mathrm{Nb}$ [41, 42] and $\mathrm{Zr}-\mathrm{Mo}$ [43, 44] alloys. The dependence of magnetic susceptibility on the $\mathrm{Nb}$ content in $\mathrm{Zr}-\mathrm{Nb}$ alloys is shown in Fig. 7.9 [41]. As is seen, the magnetic susceptibility of $\mathrm{Zr}-\mathrm{Nb}$ alloys varies as a function of $\mathrm{Nb}$ content, showing a local minimum for the $\mathrm{Nb}$ content of 3-9 mass\% [41]. As $\mathrm{Zr}$ undergoes allotropic transformation similar to $\mathrm{Ti}$, the concept of the phase stability in $\mathrm{Zr}$ alloys is similar to that of $\mathrm{Ti}$ alloys. Therefore, the phase stability of $\mathrm{Zr}$ alloys depends on the chemical composition. The allotropic transformation results in the formation of some intermediate phases, such as non-equilibrium $\alpha^{\prime}$ and $\omega$ phases, in addition to the equilibrium $\alpha$ and $\beta$ phases [41-43]. In $\mathrm{Zr}-\mathrm{Nb}$ alloys, the magnetic susceptibility of $\mathrm{Zr}-(3-9) \mathrm{Nb}$ alloys reveals local minimum with $\mathrm{Zr}-3 \mathrm{Nb}, \mathrm{Zr}-6 \mathrm{Nb}$, and $\mathrm{Zr}-9 \mathrm{Nb}$ alloys consisting of single $\alpha^{\prime}$ phase, $\left(\alpha^{\prime}+\omega+\beta\right)$ phases, and $(\omega+\beta)$ phases, respectively. However, given the volume fractions of each phase, the $\omega$ phase is considered to have the lowest magnetic susceptibilities among these phases 
Fig. 7.9 Dependence of magnetic susceptibility of $\mathrm{Zr}-\mathrm{Nb}$ alloys on niobium content [41]

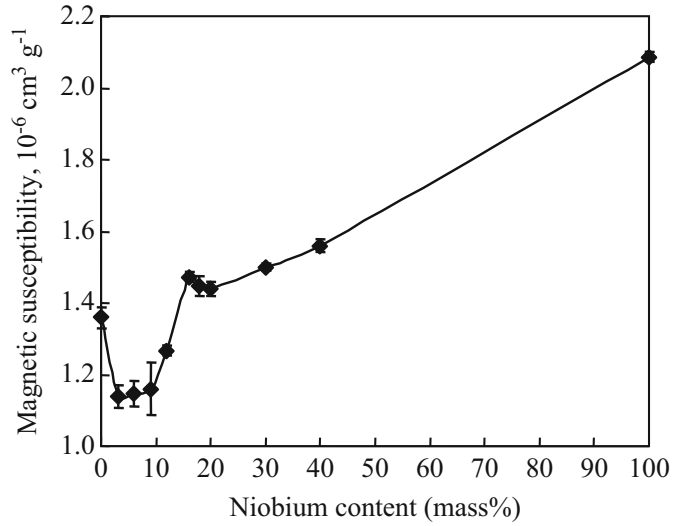

[41]. Analogously, $\mathrm{Zr}-3 \mathrm{Mo}$ alloys consist of $(\omega+\beta)$ phases, revealing the lowest magnetic susceptibility of below $1.1 \times 10^{-6} \mathrm{~cm}^{3} \mathrm{~g}^{-1}$ among both $\mathrm{Zr}-\mathrm{Nb}$ and $\mathrm{Zr}-\mathrm{Mo}$ alloys [43].

\subsection{Summary}

Metallic materials used in orthopedic implants are required to have high mechanical reliability and corrosion resistance. In addition to these conventional properties, additional value-added functionalities are being considered beneficial for the successful use of metallic materials in orthopedic implants. Therefore, in this chapter, the authors have reviewed the recent topics pertaining to the improved functionalities (low Young's modulus, self-tunable Young's modulus, and low magnetic susceptibility) of titanium and zirconium alloys via controlling the phase stability, which imparts essential functionalities to the implants. This overview is expected to facilitate a better understanding of biomedical metallic materials in potential future applications.

Acknowledgements This work was partly supported by the inter-university cooperative research program "Innovative Research for Biosis-Abiosis Intelligent Interface" from Ministry of Sports, Culture, and Education, Japan, the Industrial Technology Research Grant Program in 2009 from the New Energy and Industrial Technology Development Organization (NEDO), and Grant-in-Aid for Scientific Research (A), Young Scientists (A), and Challenging Exploratory Research from the Japan Society for the Promotion of Science (JSPS), Japan.

Open Access This chapter is distributed under the terms of the Creative Commons Attribution Noncommercial License, which permits any noncommercial use, distribution, and reproduction in any medium, provided the original author(s) and source are credited. 


\section{References}

1. Hanawa T. Research and development of metals for medical devices based on clinical needs. Sci Technol Adv Mater. 2012;13(6):064102. doi:10.1088/1468-6996/13/6/064102.

2. Hanawa T. Metals for medicine. Sendai: Japan Institute of Metals; 2010.

3. Niinomi M. Recent metallic materials for biomedical applications. Metall Mater Trans A. 2002;33(3):477-86.

4. Sumitomo N, Noritake K, Hattori T, Morikawa K, Niwa S, Sato K, et al. Experiment study on fracture fixation with low rigidity titanium alloy. J Mater Sci Mater Med. 2008;19(4):1581-6. doi:10.1007/s10856-008-3372-y.

5. Niinomi M, Nakai M, Hieda J. Development of new metallic alloys for biomedical applications. Acta Biomater. 2012;8(11):3888-903.

6. Niinomi M. Mechanical properties of biomedical titanium alloys. Mater Sci Eng A. 1998;243 (1-2):231-6.

7. Ahmed T, Long M, Silvestri J, Ruiz C, Rack HJ. A new low modulus, biocompatible titanium alloy. In: Blenkinsop PA, Evans WJ, Flower HM, editors. Titanium '95: science and technology. Birmingham: The Institute for Materials; 1996. p. 1760-7.

8. Kuroda D, Niinomi M, Morinaga M, Kato Y, Yashiro T. Design and mechanical properties of new beta type titanium alloys for implant materials. Mater Sci Eng A. 1998;243(1-2):244-9.

9. Matsumoto H, Watanabe S, Hanada S. Beta TiNbSn alloys with low Young's modulus and high strength. Mater Trans. 2005;46(5):1070-8.

10. Hao YL, Li SJ, Sun SY, Yang R. Effect of $\mathrm{Zr}$ and $\mathrm{Sn}$ on Young's modulus and superelasticity of Ti-Nb-based alloys. Mater Sci Eng A. 2006;441(1-2):112-8. doi:10. 1016/j.msea.2006.09.051.

11. Inamura T, Hosoda H, Wakashima K, Miyazaki S. Anisotropy and temperature dependence of Young's modulus in textured TiNbAl biomedical shape memory alloy. Mater Trans. 2005;46 (7):1597-603.

12. Tane M, Akita S, Nakano T, Hagihara K, Umakoshi Y, Niinomi M, et al. Peculiar elastic behavior of Ti-Nb-Ta-Zr single crystals. Acta Mater. 2008;56(12):2856-63. doi:10.1016/j. actamat.2008.02.017.

13. Matsumoto H, Watanabe S, Hanada S. Microstructures and mechanical properties of metastable beta TiNbSn alloys cold rolled and heat treated. J Alloys Compd. 2007;439(1-2):146-55. doi:10.1016/j.jallcom.2006.08.267.

14. Boyer R, Welsch G, Collings EW. Materials properties handbook: titanium alloys. Materials Park: ASM International; 1994.

15. Ozaki T, Matsumoto H, Watanabe S, Hanada S. Beta Ti alloys with low Young's modulus. Mater Trans. 2004;45(8):2776-9.

16. Hanada S. Materials properties of biomedical titanium alloys. Mater Jpn. 2008;47:242-8.

17. Fukui Y, Inamura T, Hosoda H, Wakashima K, Miyazaki S. Mechanical properties of a Ti-Nb-Al shape memory alloy. Mater Trans. 2004;45(4):1077-82.

18. Kim HY, Sasaki T, Okutsu K, Kim JI, Inamura T, Hosoda H, et al. Texture and shape memory behavior of Ti-22Nb-6Ta alloy. Acta Mater. 2006;54(2):423-33. doi:10.1016/j. actamat.2005.09.014.

19. Niinomi M. Mechanical biocompatibilities of titanium alloys for biomedical applications. J Mech Behav Biomed Mater. 2008;1(1):30-42. doi:10.1016/j.jmbbm.2007.07.001.

20. Nakai M, Niinomi M, Oneda T. Improvement in fatigue strength of biomedical beta-type Ti-Nb-Ta-Zr alloy while maintaining low Young's modulus through optimizing omega-phase precipitation. Metall Mater Trans A. 2012;43(1):294-302. doi:10.1007/s11661-011-0860-3.

21. Song X, Niinomi M, Nakai M, Tsutsumi H, Wang L. Improvement in fatigue strength while keeping low Young's modulus of a beta-type titanium alloy through yttrium oxide dispersion. Mater Sci Eng C. 2012;32(3):542-9. doi:10.1016/j.msec.2011.12.007.

22. Niinomi M. Fatigue performance and cyto-toxicity of low rigidity titanium alloy, Ti-29Nb-13Ta-4.6Zr. Biomaterials. 2003;24(16):2673-83. 
23. Narita K, Niinomi M, Nakai M, Hieda J, Oribe K. Development of thermo-mechanical processing for fabricating highly durable beta-type $\mathrm{Ti}-\mathrm{Nb}-\mathrm{Ta}-\mathrm{Zr}$ rod for use in spinal fixation devices. J Mech Behav Biomed Mater. 2012;9:207-16. doi:10.1016/j.jmbbm.2012.01.011.

24. Akahori T, Niinomi M, Fukui H, Ogawa M, Toda H. Improvement in fatigue characteristics of newly developed beta type titanium alloy for biomedical applications by thermo-mechanical treatments. Mater Sci Eng C. 2005;25(3):248-54. doi:10.1016/j.msec.2004.012.007.

25. Song X, Niinomi M, Tsutsumi H, Nakai M, Wang L. Effects of TiB on the mechanical properties of Ti-29Nb-13Ta-4.6Zr alloy for use in biomedical applications. Mater Sci Eng A. 2011;528(16-17):5600-9. doi:10.1016/j.msea.2011.03.108.

26. Lee Y-S, Niinomi M, Nakai M, Hieda J, Cho K. Wear properties of Ti-6Al-4V/Ti-29Nb-13Ta4.6Zr combination for spinal implants. Adv Mater Res. 2014;922:424-8. doi:10.4028/www. scientific.net/AMR.922.424.

27. Nakai M, Niinomi M, Hieda J, Cho K, Lee Y-S. Difference of wear behavior between Ti-29Nb-13Ta-4.6Zr alloy and Ti-6Al-4V ELI alloy for biomedical applications. TMS2014 annual meeting supplemental proceedings. 2014. p. 217-20.

28. Shi L, Wang L, Guo Z, Wu Z-X, Liu D, Gao M-X, et al. A study of low elastic modulus expandable pedicle screws in osteoporotic sheep. J Spinal Disord Tech. 2012;25(2):123-8.

29. Wang Z, Fu S, Wu Z-X, Zhang Y, Lei W. Ti2448 Pedicle screw system augmentation for posterior lumbar interbody fusion. Spine. 2013;38(23):2008-15. doi:10.1097/BRS. 0b013e3182a76fec.

30. Steib JP, Dumas R, Skalli W. Surgical correction of scoliosis by in situ contouring - a detorsion analysis. Spine. 2004;29(2):193-9.

31. Nakai M, Niinomi M, Zhao XF, Zhao XL. Self-adjustment of Young's modulus in biomedical titanium alloys during orthopaedic operation. Mater Lett. 2011;65(4):688-90. doi:10.1016/j. matlet.2010.11.006.

32. Lindsey C, Deviren V, Xu Z, Yeh RF, Puttlitz CM. The effects of rod contouring on spinal construct fatigue strength. Spine. 2006;31(15):1680-7. doi:10.1097/01.brs.0000224177. 97846.00.

33. Noshchenko A, Yao XF, Armour GA, Baldini T, Patel VV, Ayers R, et al. Evaluation of spinal instrumentation rod bending characteristics for in-situ contouring. J Biomed Mater Res B. 2011;98(1):192-200. doi:10.1002/jbm.b.31837.

34. Niinomi M, Nakai M. Titanium-based biomaterials for preventing stress shielding between implant devices and bone. Int J Biomater. 2011. doi:10.1155/2011/836587.

35. Zhao XF, Niinomi M, Nakai M, Hieda J, Ishimoto T, Nakano T. Optimization of Cr content of metastable beta-type Ti-Cr alloys with changeable Young's modulus for spinal fixation applications. Acta Biomater. 2012;8(6):2392-400. doi:10.1016/j.actbio.2012.02.010.

36. Zhao XF, Niinomi M, Nakai M, Hieda J. Beta type Ti-Mo alloys with changeable Young's modulus for spinal fixation applications. Acta Biomater. 2012;8(5):1990-7. doi:10.1016/j. actbio.2012.02.004.

37. Zhao XL, Niinomi M, Nakai M. Relationship between various deformation-induced products and mechanical properties in metastable Ti-30Zr-Mo alloys for biomedical applications. J Mech Behav Biomed Mater. 2011;4:2009-16. doi:10.1016/j.jmbbm.2011.06.020.

38. Zhao XL, Niinomi M, Nakai M, Miyamoto G, Furuhara T. Microstructures and mechanical properties of metastable Ti-30Zr-(Cr, Mo) alloys with changeable Young's modulus for spinal fixation applications. Acta Biomater. 2011;7(8):3230-6. doi:10.1016/j.actbio.2011.04.019.

39. Liu H, Niinomi M, Nakai M, Hieda J, Cho K. Deformation-induced changeable Young's modulus with high strength in beta-type Ti-Cr-O alloys for spinal fixture. J Mech Behav Biomed Mater. 2014;30:205-13. doi:10.1016/j.jmbbm.2013.11.001.

40. Uyama E, Hamada K, Asaoka K. Magnetic susceptibility and mechanical property of non-magnetic AuPtNb alloys for biomedical application. J J Dent Mater. 2010;29(5):415.

41. Nomura N, Tanaka Y, Suyalatu, Kondo R, Doi H, Tsutsumi Y, et al. Effects of phase constitution of $\mathrm{Zr}-\mathrm{Nb}$ alloys on their magnetic susceptibilities. Mater Trans. 2009;50 (10):2466-72. doi:10.2320/matertrans.M2009187. 
42. Kondo R, Nomura N, Suyalatu, Tsutsumi Y, Doi H, Hanawa T. Microstructure and mechanical properties of as-cast Zr-Nb alloys. Acta Biomater. 2011;7(12):4278-84. doi:10.1016/j.actbio. 2011.07.020.

43. Suyalatu, Nomura N, Oya K, Tanaka Y, Kondo R, Doi H et al. Microstructure and magnetic susceptibility of as-cast Zr-Mo alloys. Acta Biomater. 2010;6(3):1033-8. doi:10.1016/j.actbio. 2009.09.013.

44. Suyalatu, Kondo R, Tsutsumi Y, Doi H, Nomura N, Hanawa T. Effects of phase constitution on magnetic susceptibility and mechanical properties of Zr-rich Zr-Mo alloys. Acta Biomater. 2011;7(12):4259-66. doi:10.1016/j.actbio.2011.07.005. 